\title{
Effects of Two Current Great Saphenous Vein Thermal Ablation Methods on Visual Analog Scale and Quality of Life
}

\author{
Soner Sanioglu, Halit Yerebakan, and Mustafa Bora Farsak \\ Department of Cardiovascular Surgery, Yeditepe University Hospital, Istanbul, Turkey \\ Correspondence should be addressed to Soner Sanioglu; sanioglu@gmail.com
}

Received 18 April 2017; Accepted 17 September 2017; Published 16 November 2017

Academic Editor: Nikolaos Siafakas

Copyright (C) 2017 Soner Sanioglu et al. This is an open access article distributed under the Creative Commons Attribution License, which permits unrestricted use, distribution, and reproduction in any medium, provided the original work is properly cited.

\begin{abstract}
Background. The aim of the study is to compare the current two endovenous thermal ablation methods by examining the effects on the visual analog scale (VAS) and the short form-36 ${ }^{\circledR}$ quality of life index. Methods. Ninety-six patients who underwent unilateral endovenous thermal ablation of great saphenous vein were included. ClosureFast ${ }^{\mathrm{TM}}$ catheters were used in the RFA group and $1470 \mathrm{~nm}$ radial fiber laser catheters were used in the EVLA group. Results. The RFA group consisted of 41 patients and the EVLA group consisted of 55 patients. The preoperative baseline characteristics of both groups were similar. On the day of operation, VAS values were $2.8 \pm 1.1$ in the RFA group and $3.6 \pm 1.8$ in the EVLA group $(p=0.02)$. Comparisons of short form-36 parameters in both groups showed them to be similar except the pain detected at postoperative 1st week ( $48.1 \pm 5.4$ for RFA, $44.9 \pm 7.6$ for EVLA, $p=0.04)$. Conclusion. Results in postprocedural quality of life were found to be similar in both of the techniques. However, in terms of postoperative pain, radiofrequency ablation is still superior to the $1470 \mathrm{~nm}$ radial fiber laser catheters.
\end{abstract}

\section{Introduction}

According to current guidelines thermal ablation is the first choice of treatment in saphenous vein insufficiency $[1,2]$. Among those, radiofrequency ablation (RFA) and endovenous laser ablation (EVLA) are the most commonly used. There is no consensus about the superiority of these techniques. Although lesser pain and complication rate was reported with RFA, using old generation laser catheters in those studies has led to question of the superiority of the RFA [3-6]. Because of this, new studies are needed with the use of new generation catheters with high wave length and new tip designs. Advances in laser catheters may alter the results and end the superiority of the RFA [7-9].

Short form-36 (SF-36 $\left.{ }^{\circledR}\right)$ is frequently used questionary with 36 questions in quality of life analysis. SF-36 uses 8 parameters to detect physical and mental status (physical function, physical role, pain, and general health for physical component; vitality, social role, emotional role, and mental health for mental component) [10]. Visual analog scala (VAS) is used to evaluate pain objectively. The purpose of this study is to compare the postoperative results of two current thermal ablation methods and their effects on VAS and SF-36 quality of life index.

\section{Materials and Methods}

2.1. Patient Groups. One hundred fifteen patients underwent great saphenous vein (GSV) thermal ablation between February 2013 and March 2016 at our institution. Among them, ninety-six patients undergoing unilateral GSV endovenous thermal ablation were enrolled in the study. Local anesthesia and mild midazolam sedation were used in all patients. Patient with previous deep vein thrombosis, accessory saphenous vein insufficiency, previous venous surgery in the same extremity, peripheral arterial disease $(\mathrm{ABI}<0.8)$, patients with CEAP [11] class C4b and above, and immobilized patients were excluded from the study. The information of the patient was obtained by examining the hospital records. Patients were separated into RFA and EVLA groups.

2.2. Radiofrequency Ablation. The GSV was cannulated percutaneously using an 18-gauge needle with the aid of ultrasound on the knee area. A $6 \mathrm{~F}$ introducer sheath (INPUT 
Introducer Sheath, Medtronic Ireland Parkmore Business Park West, Galway, Ireland) was introduced to GSV over a guide wire, inserted through the needle used in cannulation. ClosureFast radiofrequency ablation catheter (VNUS ${ }^{\circledR}$ ClosureFast, Covidien, Dublin, Ireland) was inserted into the vein through this sheath and advanced until $2 \mathrm{~cm}$ below the saphenofemoral junction, guided by ultrasound. Following infiltration of perivenous field with tumescent anesthesia $(500 \mathrm{ml}$ saline $0.9 \%, 50 \mathrm{mg}$ Marcaine $0.5 \%, 0,5 \mathrm{ml}$ epinephrine 1:1000, and $50 \mathrm{mEq} \mathrm{NaHCO}_{3}$ ) ablation was performed twice for the first segment and once for the other segments with recommended energy setup.

2.3. Endovenous Laser Ablation. The GSV was cannulated in the same manner. A radial laser probe (Elves radial, Bolitec AG, Bonn, Germany) was inserted into the vein through sheath and advanced until $2 \mathrm{~cm}$ below the saphenofemoral junction, guided by ultrasound. Following infiltration of perivenous field with identical tumescent anesthesia, ablation was performed at linear endovenous energy density of $70 \mathrm{~J} / \mathrm{cm}$ by a $1470 \mathrm{~nm}$ diode laser.

Preoperative diameter of the saphenous vein at the saphenofemoral junction, the length of ablated segment, and amount of tumescent used were recorded in both of the groups. Cutaneous varicose veins were excised in the same operating session using mini phlebectomy method. Before finishing the procedure, closure of GSV and patency of femoral vein were controlled by Doppler ultrasound. The procedure was finalized following compression bandaging of the leg.

A deep vein thrombosis prophylaxis was given using $0.1 \mathrm{U} / \mathrm{kg}$ of low molecular weight heparin to all patients and 1 gram paracetamol was ordered at the second hour postoperatively. After that compression bandages were removed and patients were dressed with grade II $(23-32 \mathrm{mmHg})$ compression stockings and they were mobilized. Patients without clinical problems were discharged on the same day of surgery. Just before being discharged, their postoperative pain was evaluated by VAS (0: no pain, 10: severe pain requesting bed resting). It was advised that compression stockings be used only during daytime after the first 24 hours had passed. Compression treatment was stopped following the control examination on postoperative day 7.

2.4. Follow-Up Protocol. All patients were referred to the outpatient clinic at the first postoperative week, 3rd month, 6 th month, and then once a year. The records of the patients were examined and the pre- and posttreatment CEAP class, venous clinical severity score [12] (VCSS), VAS, and SF36 quality of life index values were determined. When the quality of life indexes of the patients were calculated, the Turkish version of the SF-36 form and the application at "www.sf-36.org/demos/SF-36.html" were used. Sclerotherapy was suggested to patients with CEAP class $C_{1}$ varicose veins at the third month of follow-up. Postoperative complications and recurrences during follow-up were recorded. Control Doppler USG was not routinely performed on every patient. For this reason, recanalization rates were not evaluated in the study.
2.5. Statistical Analysis. Minimal clinically significant difference for postoperative VAS between groups was accepted as one (estimated standard deviation was 1,5). Cohen's $d$ was 0,66 and the minimum number of patients for each groups was 38 for $80 \%$ power. Nonparametric variables of the patients were expressed as a percentage, and parametric variables were expressed as mean \pm standard deviation. The normal distribution was assessed by the KolmogorovSmirnov test. When comparing groups, independent-sample $t$-test was used when the distribution was normal, while when it was not normal Mann-Whitney $U$ test was used. The $\chi^{2}$ test was used to compare the nonparametric data of the groups. Fisher's exact test was preferred when the nonparametric variables were below 5 during the comparisons. For evaluating effects of the operation on the SF-36 quality of life index, when the distribution was normal the paired-sample $t$-test was used; otherwise Wilcoxon Rank Sum test was used. A value of $p<0.05$ was considered statistically significant. All analyses were performed using the SPSS 15.0 program for Windows (SPSS Inc., Chicago, IL, USA).

\section{Results and Discussion}

3.1. Results. Ninety-six patients were included in the study. The RFA group consisted of 41 patients and the EVLA group consisted of 55 patients. The mean age was $46 \pm 12$ in the RFA group and $45 \pm 10$ in the EVLA group. Most of the patients in both groups consisted of female patients. At the saphenofemoral junction level, the diameter of the GSV was $8.8 \pm 2.5 \mathrm{~mm}$ in the RFA group and $9.5 \pm 2.7 \mathrm{~mm}$ in the EVLA group. Preoperative VCSS was $4.3 \pm 1.7$ in the RFA group and $4.4 \pm 1.2$ in the EVLA group and VAS was $5 \pm 2$ in the RFA group and $5.1 \pm 1.8$ in the EVLA group. Most of the patients in both groups were in class $\mathrm{C}_{2}-\mathrm{C}_{3}$. There was no significant difference between groups in terms of age, gender, comorbid disease, preoperative CEAP class, VCSS, GSV diameter, VAS, and SF-36 quality of life index (Table 1).

The success rate was $100 \%$ in both groups. The ablated segment was $27 \pm 1 \mathrm{~cm}$ in the RFA group and $26 \pm 1 \mathrm{~cm}$ in the EVLA group $(p=0.73)$. No statistically significant difference was found in the use of amount of tumescent anesthesia between the two groups $(380 \pm 22$ versus $385 \pm 18 \mathrm{ml}, p=$ $0,96)$. The number of mini phlebectomy procedures for local varicose veins was $3.4 \pm 0.7$ in the RFA group and $3.6 \pm 0.7$ in the EVLA group $(p=0.3)$. All of the patients were discharged on the day of the procedure.

The mean follow-up was $11 \pm 8$ months in the RFA group and $14 \pm 9$ months in the EVLA group. Six months' followup was achieved in all the patients studied (100\%), while 10 patients $(20 \%)$ did not show up on their first-year control. During the follow-up period, $4(10 \%)$ patients in the RFA group and $6(11 \%)$ in the EVLA group had complications $(p=$ $0.85)$. None of the patients had skin burns or deep venous thrombosis. The distribution of developing complications according to the groups is listed in Table 2. The recurrence rate was $1(2.4 \%)$ in RFA group and $2(3.6 \%)$ in the EVLA group $(p=0.73)$. Two of the patients were treated with high ligation and one was treated with foam sclerotherapy. 
TABLE 1: Comparison of preoperative variables of the groups: There is no significant difference between two groups.

\begin{tabular}{|c|c|c|c|}
\hline & RFA $(n=41)$ & EVLA $(n=55)$ & $p$ value \\
\hline Age & $46 \pm 12$ & $45 \pm 10$ & 0.77 \\
\hline Female/male & $27 / 14$ & $38 / 17$ & 0.73 \\
\hline \multicolumn{4}{|l|}{ Comorbidities } \\
\hline Hypertension (\%) & $6(14.6)$ & $7(12.7)$ & 0.78 \\
\hline Diabetes (\%) & $3(7,3)$ & $4(7.3)$ & 0.99 \\
\hline CAD (\%) & $2(4.9)$ & $3(5.5)$ & 0.90 \\
\hline Others (\%) & $3(7.3)$ & $5(9.1)$ & 0.75 \\
\hline \multicolumn{4}{|l|}{ CEAP class } \\
\hline $\mathrm{C}_{1}(\%)$ & $1(2)$ & $1(2)$ & 0.83 \\
\hline $\mathrm{C}_{2}(\%)$ & $24(59)$ & $34(61)$ & 0.74 \\
\hline $\mathrm{C}_{3}(\%)$ & $15(37)$ & $19(35)$ & 0.83 \\
\hline $\mathrm{C}_{4 \mathrm{a}}(\%)$ & $1(2)$ & $1(2)$ & 0.83 \\
\hline GSV diameter $(\mathrm{mm})$ & $8.8 \pm 2.5$ & $9.5 \pm 2.7$ & 0.22 \\
\hline VCSS & $4.3 \pm 1.7$ & $4.4 \pm 1.2$ & 0.60 \\
\hline Preop VAS & $5 \pm 2$ & $5.1 \pm 1.8$ & 0,83 \\
\hline \multicolumn{4}{|l|}{ SF-36 parameters } \\
\hline Physical function & $48.5 \pm 7.1$ & $47.7 \pm 6.6$ & 0.39 \\
\hline Physical role & $50.2 \pm 9.8$ & $48.6 \pm 10.4$ & 0.43 \\
\hline Pain & $43.5 \pm 9.7$ & $43.1 \pm 7.8$ & 0.75 \\
\hline General health & $50.3 \pm 8$ & $49.5 \pm 7.0$ & 0.27 \\
\hline Vitality & $53.4 \pm 7.5$ & $52.8 \pm 9$ & 0.75 \\
\hline Social role & $49.1 \pm 9$ & $49 \pm 8.4$ & 0.79 \\
\hline Emotional role & $50.9 \pm 10$ & $50.7 \pm 10.5$ & 0.92 \\
\hline Mental health & $46.8 \pm 8$ & $46.5 \pm 9.2$ & 0.58 \\
\hline Physical component score & $46.4 \pm 8.8$ & $44.8 \pm 7.8$ & 0.31 \\
\hline Mental component score & $50.5 \pm 9.3$ & $50.6 \pm 9.2$ & 0.92 \\
\hline
\end{tabular}

CAD: coronary artery disease, VAS: visual analog scale, VCSS: venous clinical severity score, GSV: great saphenous vein, and SF-36: short form-36.

TABLE 2: Postoperative complications: There is no significant difference between two groups.

\begin{tabular}{lccc}
\hline & RFA $(n=41)$ & EVLA $(n=55)$ & $p$ value \\
\hline Complications (\%) & $4(10)$ & $6(11)$ & 0.85 \\
Hyperpigmentation (\%) & $1(2.4)$ & $2(3.6)$ & \\
Endurance (\%) & $2(4.9)$ & $3(5.5)$ & \\
Paresthesia (\%) & $1(2.4)$ & - & \\
Cellulitis (\%) & - & $1(1.8)$ & \\
Skin burn (\%) & - & - & \\
DVT (\%) & - & - & \\
\hline
\end{tabular}

The improvements in the postoperative CEAP classifications were shown in Table 3. In the first week, it was observed that the majority of the patients in both groups tended to be in the class $\mathrm{C}_{0}-\mathrm{C}_{1}$ and this clinical improvement was maintained throughout the follow-up period. In both groups, mean VCSS were found to decrease compared to preoperative level in the first week, but significant improvement was observed at the 3rd month (Figure 1). The delay in correction was due to mandatory compression therapy applied to all patients during the first postoperative week. When the mean VCSS obtained during follow-up were compared, no significant difference was found between the two groups.
The VAS value determined on the day of operation was $2.8 \pm 1.1$ in the RFA group and $3.6 \pm 1.8$ in the EVLA group. The difference between the two groups was statistically significant $(p=0.02)$ (Figure 2).

Changes in the SF-36 quality of life index parameters following the operation are shown in Table 4. When the two groups were compared, it was seen that all parameters were similar except for the pain that was observed at 1st week $(48.1 \pm 5.4$ for RFA and $44.9 \pm 7.6$ for EVLA, $p=0.04)$. When the effect of ablation on the quality of life was examined, similar changes were observed for both methods (Tables 1 and 2). In the first week, physical function, physical role, and social role parameters decreased significantly, but general health, emotional role, and mental health parameters did not change significantly in both groups. Viability increased significantly in both groups but the improvement in the pain parameters was significant in the RFA group and was not significant in the EVLA group $(p=0.03, p=0.13)$. It was found that the physical component score decreased and the mental component score increased significantly in both groups. At the third month of evaluation, it was observed that the decrease in physical function, physical role, and social role disappeared in both of the groups and that the preoperative values were significantly exceeded. The general health parameters were significantly increased in both 
TABLE 3: Postoperative changes of the CEAP clinical classification of the patients: both of the groups consist of mostly class $\mathrm{C}_{2}-\mathrm{C}_{3}$ patients. Postoperative improvements for the CEAP clinic class were maintained during follow-up.

\begin{tabular}{|c|c|c|c|c|c|}
\hline & Preop & 1st week & 3rd month & 6th month & 1st year \\
\hline & \multicolumn{5}{|c|}{$\operatorname{RFA}(n=41)$} \\
\hline $\mathrm{C}_{0}(\%)$ & $0(0)$ & $14(34)$ & $14(34)$ & $21(52)$ & $8(62)$ \\
\hline $\mathrm{C}_{1}(\%)$ & $1(2)$ & $26(64)$ & $26(64)$ & $18(44)$ & $4(30)$ \\
\hline $\mathrm{C}_{2}(\%)$ & $24(59)$ & $0(0)$ & $0(0)$ & $1(2)$ & $0(0)$ \\
\hline $\mathrm{C}_{3}(\%)$ & $15(37)$ & $0(0)$ & $0(0)$ & $0(0)$ & $0(0)$ \\
\hline \multirow[t]{2}{*}{$\mathrm{C}_{4 \mathrm{a}}(\%)$} & $1(2)$ & $1(2)$ & $1(2)$ & $1(2)$ & $1(8)$ \\
\hline & \multicolumn{5}{|c|}{$\operatorname{EVLA}(n=55)$} \\
\hline $\mathrm{C}_{0}(\%)$ & $0(0)$ & $25(45)$ & $25(45)$ & $32(58)$ & $17(63)$ \\
\hline $\mathrm{C}_{1}(\%)$ & $1(2)$ & $27(49)$ & $28(51)$ & $21(38)$ & $9(33)$ \\
\hline $\mathrm{C}_{2}(\%)$ & $34(61)$ & $0(0)$ & $1(2)$ & $1(2)$ & $0(0)$ \\
\hline $\mathrm{C}_{3}(\%)$ & $19(35)$ & $2(4)$ & $0(0)$ & $0(0)$ & $0(0)$ \\
\hline $\mathrm{C}_{4 \mathrm{a}}(\%)$ & $1(2)$ & $1(2)$ & $1(2)$ & $1(2)$ & $1(4)$ \\
\hline
\end{tabular}

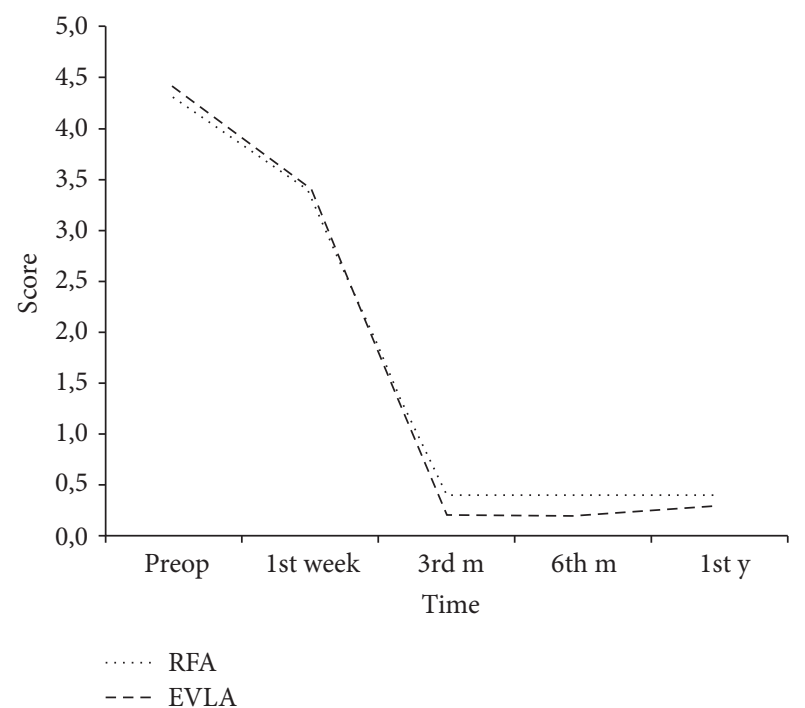

FIGURE 1: Postoperative changes for VCSS of both groups: similar improvements were detected for VCSS of both groups during followup (VCSS: venous clinical severity score).

groups, while the emotional role and mental health parameters remained unchanged. It was observed that the increase in the first week observed in the vitality parameters in both groups continued increasing at the third month. Contrary to the first week, it was found that the development of the pain parameter became meaningful in both groups and the difference disappeared. It was seen that the decrease in physical component score in the first week was significantly increased at the third month and exceeded preoperative values and the increase in mental component score was decreased to below the preoperative values. At the 6th-month and 1st-year controls, it was found that the changes in the third month remained largely stable, and only the mental component score reached the preoperative values again.

3.2. Discussion. When the findings are examined, it can be said that both ablation methods have similar high clinical

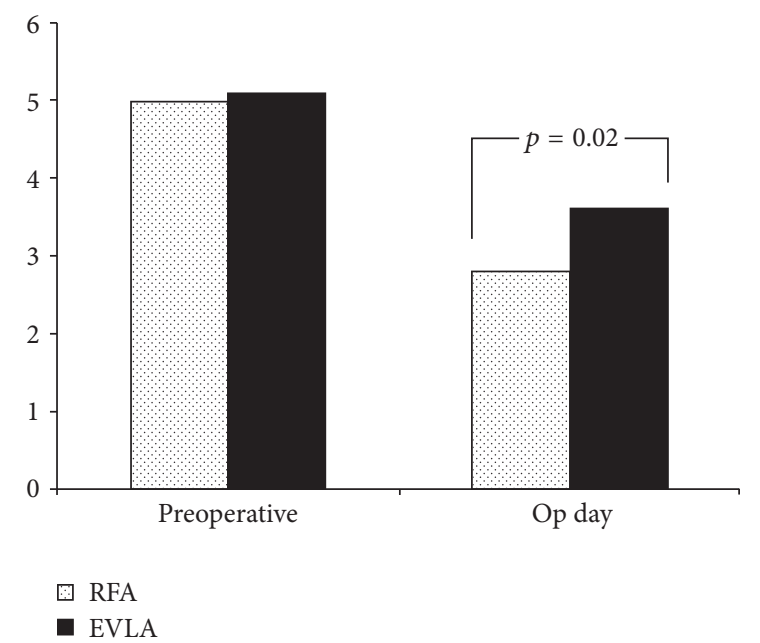

FIGURE 2: Comparison of mean preoperative and operative day VAS between two groups: preoperative VAS was similar for both groups, but operative day VAS in RFA group was significantly lower than in EVLA group (VAS: visual analog scale).

success and low complication rates. In the first week postoperatively, SF-36 resulted in a decrease in both physical component and social role scores, but, in later controls, the quality of life was found to be above preoperative levels in almost all parameters. The only significant difference between the groups was the severity of pain experienced after ablation. In the RFA group on the day of operation, the pain assessed by VAS was significantly lower than in the EVLA group (Figure 2). A significant difference was found between the two groups in the SF-36 quality of life index pain parameter on the first week and it was found that this difference between the two groups disappeared in later controls (Table 4). These results suggest that in our study group RFA caused less pain on the operation day and that this advantage continued for the first postoperative week. As is known, the level of evidence for retrospective studies is lower than that for prospective randomizations. However, the 
TABLE 4: Postoperative changes for SF-36 parameters: postoperative changes for the quality of life index are similar for both groups except pain parameter in the first week.

\begin{tabular}{|c|c|c|c|}
\hline SF-36 parameters & RFA $(n=41)$ & EVLA $(n=55)$ & $p$ value \\
\hline \multicolumn{4}{|c|}{ 1st week } \\
\hline Physical function & $43.6 \pm 6.7$ & $43.3 \pm 6.8$ & 0.99 \\
\hline Physical role & $39.3 \pm 7.2$ & $38.0 \pm 8.7$ & 0.19 \\
\hline Pain & $48.1 \pm 5.4$ & $44.9 \pm 7.6$ & 0.04 \\
\hline General health & $50.5 \pm 8$ & $50.2 \pm 7.5$ & 0.58 \\
\hline Vitality & $54 \pm 7.5$ & $53.8 \pm 8.9$ & 0.85 \\
\hline Social role & $46 \pm 8.3$ & $44.2 \pm 8.9$ & 0.27 \\
\hline Emotional role & $50.4 \pm 10$ & $48.6 \pm 11.7$ & 0.53 \\
\hline Mental health & $46.8 \pm 7.8$ & $46.9 \pm 8.5$ & 0.61 \\
\hline Physical component score & $41.7 \pm 5.6$ & $40.4 \pm 6.6$ & 0.30 \\
\hline Mental component score & $52 \pm 8.3$ & $51.3 \pm 9.3$ & 0.41 \\
\hline \multicolumn{4}{|c|}{ 3rd month } \\
\hline Physical function & $54.1 \pm 5$ & $54.3 \pm 3$ & 0.55 \\
\hline Physical role & $55.5 \pm 2.6$ & $55.4 \pm 2.2$ & 0.58 \\
\hline Pain & $62 \pm 2.5$ & $60.1 \pm 5$ & 0.13 \\
\hline General health & $51.9 \pm 7.7$ & $51.1 \pm 7.0$ & 0.37 \\
\hline Vitality & $56.2 \pm 6.8$ & $55.6 \pm 7.7$ & 0.60 \\
\hline Social role & $51,8 \pm 6.5$ & $52.2 \pm 6.9$ & 0.50 \\
\hline Emotional role & $51.7 \pm 9$ & $51.5 \pm 9.4$ & 0.96 \\
\hline Mental health & $47.7 \pm 7$ & $47.5 \pm 8$ & 0.73 \\
\hline Physical component score & $56.6 \pm 4.7$ & $56 \pm 3.6$ & 0.18 \\
\hline Mental component score & $49 \pm 7.3$ & $49 \pm 8.2$ & 0.96 \\
\hline \multicolumn{4}{|c|}{ 6th month } \\
\hline Physical function & $54.6 \pm 4.6$ & $54.6 \pm 3.2$ & 0.66 \\
\hline Physical role & $55.7 \pm 1.8$ & $55.6 \pm 2.4$ & 0.98 \\
\hline Pain & $61,7 \pm 2.5$ & $61.2 \pm 3.7$ & 0.71 \\
\hline General health & $53.1 \pm 7.6$ & $52.5 \pm 7.0$ & 0.38 \\
\hline Vitality & $56.4 \pm 6.6$ & $56.8 \pm 7.8$ & 0.95 \\
\hline Social role & $52.1 \pm 6.1$ & $53 \pm 6.3$ & 0.34 \\
\hline Emotional role & $53 \pm 7.6$ & $51.7 \pm 8.6$ & 0.27 \\
\hline Mental health & $48.5 \pm 6.6$ & $48.7 \pm 7.9$ & 0.86 \\
\hline Physical component score & $56.8 \pm 4.4$ & $56.6 \pm 3.6$ & 0.32 \\
\hline Mental component score & $50.7 \pm 7$ & $50 \pm 8.1$ & 0.96 \\
\hline \multicolumn{4}{|c|}{ 1st year } \\
\hline Physical function & $55.6 \pm 2.5$ & $55.2 \pm 2.3$ & 0.50 \\
\hline Physical role & $56.2 \pm 0.1$ & $55.6 \pm 1.3$ & 0.85 \\
\hline Pain & $61,1 \pm 3$ & $60.9 \pm 3.6$ & 0.96 \\
\hline General health & $55.2 \pm 8.1$ & $53.6 \pm 8.1$ & 0.55 \\
\hline Vitality & $56.7 \pm 6.3$ & $57.9 \pm 7.6$ & 0.53 \\
\hline Social role & $53.8 \pm 4.7$ & $54.8 \pm 5.2$ & 0.43 \\
\hline Emotional role & $52.9 \pm 8.8$ & $53.1 \pm 6$ & 0.79 \\
\hline Mental health & $48.7 \pm 4.3$ & $49.5 \pm 7.4$ & 0.72 \\
\hline Physical component score & $57.8 \pm 3.1$ & $57 \pm 3.4$ & 0.39 \\
\hline Mental component score & $50.3 \pm 6.4$ & $51.4 \pm 7.6$ & 0.72 \\
\hline
\end{tabular}

SF-36: short form-36.

relatively homogeneous formation of the groups (Table 1), the similarity of the factors that can affect the postoperative pain, such as the ablated segment length, the amount of tumescent used, the number of phlebectomy procedures, and the anesthesia protocol increase the reliability of the results.

SF-36 is widely used in assessing quality of life. It is known that particularly physical function, physical role, pain, and general health parameters are in compliance with the severity of venous diseases, while compliance was not great in vitality, social role, emotional role, and mental health parameters that constitute the mental component [1]. Our results confirm these findings. It was observed that the improvement obtained after operation in the physical component parameters did not occur in all of the mental component parameters. Emotional role and mental health parameters were not significantly changed during treatment, and mental component, which is one of the main two components, was worsened at 3rd month, but it was found to increase again back to preoperative levels at 6th-month and 1st-year controls. It can be said that both ablation methods decrease the quality of life temporarily during the first week postoperatively, but it can be assumed that it is improved afterwards 
when we look at the physical component scores. In the mental component scores, the treatment modality does not seem to lead a change when we exclude the early period.

RFA revealed superior results in complication rates and postoperative pain in most of the studies [3-6]. Developments in laser catheters have led to improvements in EVLA results, and it is thought that the new catheters could end this superiority of RFA $[7,8]$. However, this hypothesis has not been sufficiently questioned. There is only one study in the literature comparing RFA with current laser catheters. Bozoglan et al. used RFA and $1470 \mathrm{~nm}$ radial fiber laser catheter in two different extremities of the same patient and reported that EVLA was superior to RFA in terms of postoperative pain and rate of return to daily activity [9]. Our findings are not compatible with this study. In terms of postoperative pain according to our results, RFA still seems advantageous against the $1470 \mathrm{~nm}$ radial fiber laser catheter. Using of a rarely preferred RFA catheter was the drawback of Bozoglan's study. There could be differences in between RFA catheters as in laser catheters. The higher complication rates in the used catheters versus VNUS ClosureFast are even published in their official web site [13]. No other study comparing two RFA catheters in the literature has been found. It is clear that further studies are needed. On the other hand, it should not be overlooked that the developmental process of laser catheters is still ongoing. It has been shown that better results can be obtained with higher wave length and more different tip designs than $1470 \mathrm{~nm}$ radial fiber [14, 15]. While questioning which endovenous thermal ablation method is superior, this should be kept in mind.

\section{Conclusions}

As a result, two current thermal ablation methods commonly used in the treatment of GSV insufficiency have similarly high clinical success and low complication rates. Both methods provide a significant improvement in the quality of life. In terms of postoperative pain, the superiority of RFA in previous studies seems to be still maintained against $1470 \mathrm{~nm}$ radial fiber laser catheters. New randomized multicenter studies are needed to achieve a final result.

\section{Conflicts of Interest}

The authors declare that they have no conflicts of interest.

\section{References}

[1] C. Wittens, A. H. Davies, N. Bækgaard, R. Broholm, A. Cavezzi, S. Chastanet et al., "European society for vascular surgery. editor's choice - management of chronic venous disease: clinical practice guidelines of the european society for vascular surgery (ESVS)," European Journal of Vascular and Endovascular Surgery, vol. 49, no. 6, pp. 678-737, 2015.

[2] P. Gloviczki, A. J. Comerota, M. C. Dalsing et al., "The care of patients with varicose veins and associated chronic venous diseases: clinical practice guidelines of the Society for Vascular Surgery and the American Venous Forum," Journal of Vascular Surgery, vol. 53, no. 5, supplement, pp. 2S-48S, 2011.
[3] J. I. Almeida, J. Kaufman, O. Göckeritz et al., "Radiofrequency endovenous closure FAST versus laser ablation for the treatment of great saphenous reflux: a multicenter, single-blinded, randomized study (RECOVERY Study)," Journal of Vascular and Interventional Radiology, vol. 20, no. 6, pp. 752-759, 2009.

[4] S. S. Gale, J. N. Lee, M. E. Walsh, D. L. Wojnarowski, and A. J. Comerota, "A randomized, controlled trial of endovenous thermal ablation using the $810-\mathrm{nm}$ wavelength laser and the ClosurePLUS radiofrequency ablation methods for superficial venous insufficiency of the great saphenous vein," Journal of Vascular Surgery, vol. 52, no. 3, pp. 645-650, 2010.

[5] S. D. Goode, A. Chowdhury, M. Crockett et al., "Laser and radiofrequency ablation study (LARA study): a randomised study comparing radiofrequency ablation and endovenous laser ablation (810 nm)," European Journal of Vascular and Endovascular Surgery, vol. 40, no. 2, pp. 246-253, 2010.

[6] I. M. Nordon, R. J. Hinchliffe, R. Brar et al., "A prospective double-blind randomized controlled trial of radiofrequency versus laser treatment of the great saphenous vein in patients with varicose veins," Annals of Surgery, vol. 254, no. 6, pp. 876881, 2011.

[7] W. S. J. Malskat, J. Giang, M. G. R. De Maeseneer, T. E. C. Nijsten, and R. R. Van Den Bos, "Randomized clinical trial of 940- versus 1470-nm endovenous laser ablation for great saphenous vein incompetence," British Journal of Surgery, vol. 103, no. 3, pp. 192-198, 2016.

[8] M. Hirokawa and N. Kurihara, "Comparison of Bare-Tip and Radial Fiber in Endovenous Laser Ablation with $1470 \mathrm{~nm}$ Diode Laser," Annals of Vascular Diseases, vol. 7, no. 3, pp. 239-245, 2014.

[9] O. Bozoglan, B. Mese, E. Eroglu et al., "Comparison of endovenous laser and radiofrequency ablation in treating varicose veins in the same patient," Vascular and Endovascular Surgery, vol. 50, no. 1, pp. 47-51, 2016.

[10] J. E. Ware Jr. and B. Gandek, "Overview of the SF-36 health survey and the International Quality of Life Assessment (IQOLA) Project," Journal of Clinical Epidemiology, vol. 51, no. 11, pp. 903912, 1998.

[11] Reporting standarts in venous disease, "Prepared by the subcommittee on reporting standards in venous disease, ad hoc committee on reporting standarts, Society for Vascular Surgery/North American Chapter, International Society for Cardiovascular Surgery," Journal of Vascular Surgery, vol. 8, no. 4, pp. 172-181, 1988.

[12] R. B. Rutherford, F. T. Padberg Jr., A. J. Comerota, R. L. Kistner, M. H. Meissner, and G. L. Moneta, "Venous severity scoring: An adjunct to venous outcome assessment," Journal of Vascular Surgery, vol. 31, no. 6, pp. 1307-1312, 2000.

[13] P. Lingam, Tan J. Z., Q. Hong, S. Chandrassekar, s. Narayanan et al., 2017, Comparison of EVRF versus VNUS in Radiofrequency Ablation of Chronic Venous Insufficiency http://fcaresystems .com/wp-content/uploads/2012/11/Comparison-of-EVRF-versusVNUS.pdf.

[14] T. Yamamoto and M. Sakata, "Influence of fibers and wavelengths on the mechanism of action of endovenous laser ablation," Journal of Vascular Surgery: Venous and Lymphatic Disorders, vol. 2, no. 1, pp. 61-69, 2014.

[15] D. Mendes-Pinto, P. Bastianetto, L. Cavalcanti Bragalyra, R. Kikuchi, and L. Kabnick, "Endovenous laser ablation of the great saphenous vein comparing $1920-\mathrm{nm}$ and $1470-\mathrm{nm}$ diode laser," International Angiology, vol. 35, no. 6, pp. 599-604, 2016. 


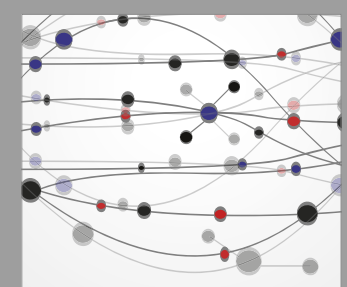

The Scientific World Journal
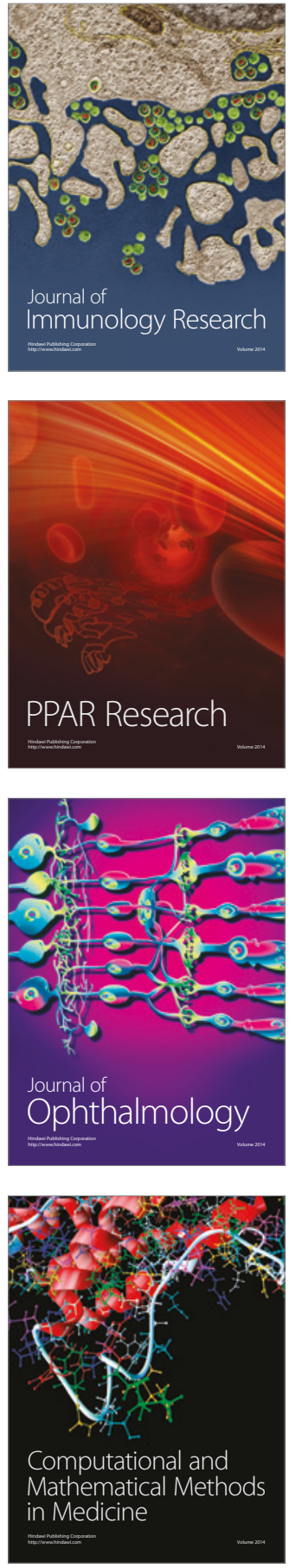

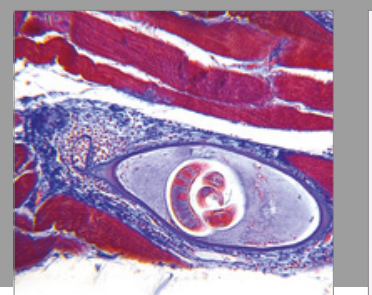

Gastroenterology Research and Practice
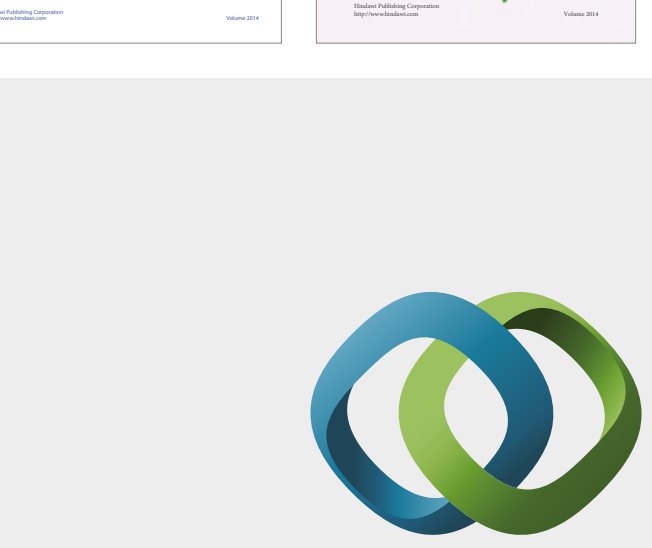

\section{Hindawi}

Submit your manuscripts at

https://www.hindawi.com
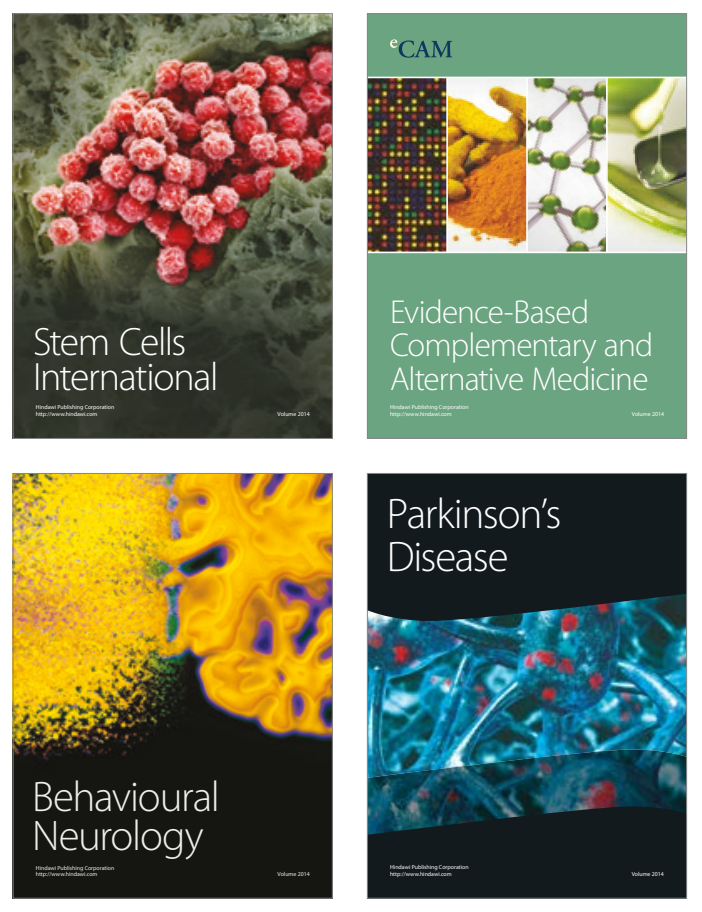
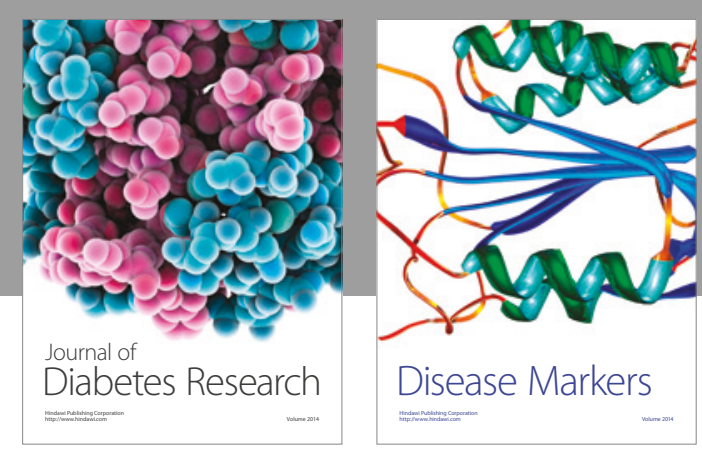

Disease Markers
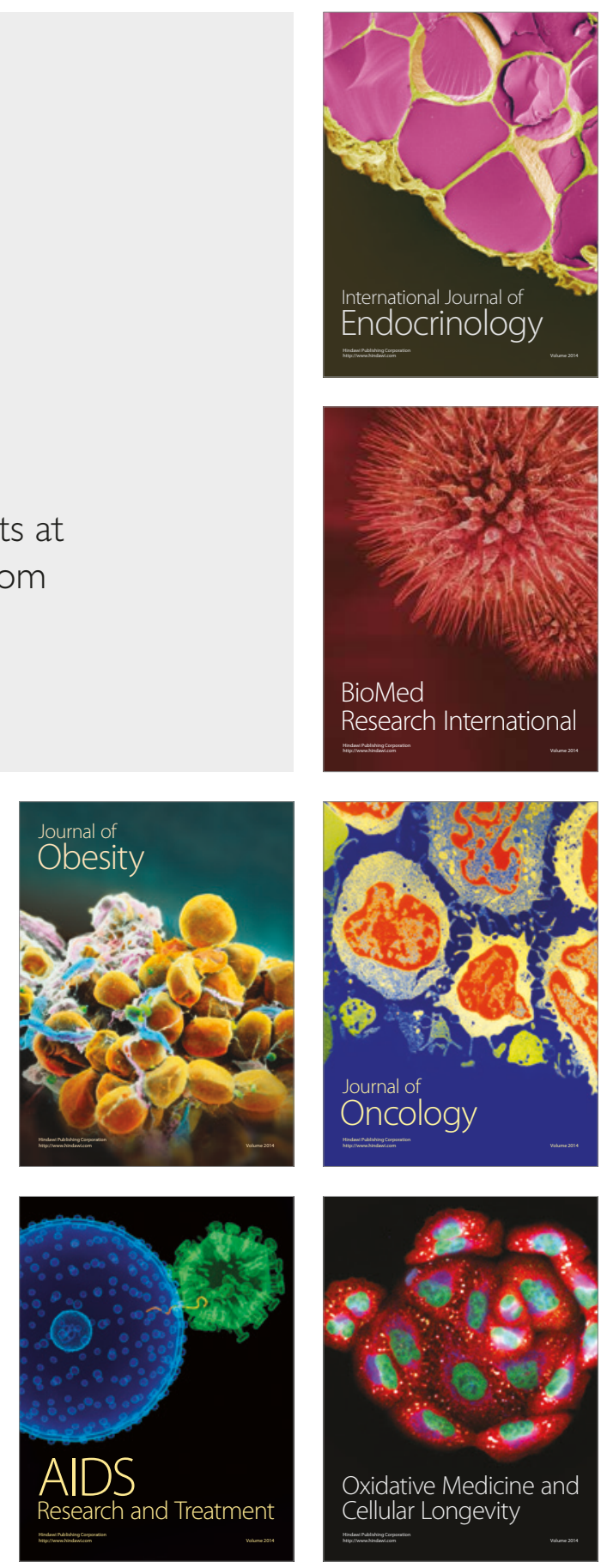